\title{
Study on Mechanism of Frost Heaving and Thawing in Construction of Tunnel-Channel Freezing Method
}

\author{
Nsoro Fabrice, Dr. Luo Zhan You \\ School of Civil Engineering \\ Zhejiang University of Science and Technology, Hangzhou PR China
}

\begin{abstract}
Artificial soil freezing technique is a well-proven soil improvement approach used worldwide to construct tunnels and many other civil structures in difficult subsoil or ambient conditions. We present quantitatively mechanism and the analyzing results from the applications monitoring of artificial soil freezing in tunnel construction projects. The interpretation of the field measurements is based on coupled computation simulations using the Abacus software for the freezing simulation analysis where the emphasis was on a realistic simulation of the overall project situation during the frozen body growth stage. The case study relates to a platform tunnel in a station of Hangzhou City Rail Transit Line 5 Line 16 Standard Jiangnan Avenue Station - Jianghong Road West Station Zone 1 metro with the aims to determine missing but relevant material parameters via back analysis and to make comparisons of model predictions with field measurements and considerable construction delays occurred due to the inability to create a completely closed frozen body. Field monitoring and modeling activities to enhance our understanding of the mechanical integrity of freeze wall containment system will also be briefly introduced.
\end{abstract}

Keywords: Artificial Soil Freezing, Tunnel, Mechanism, Simulation

DOI: $10.7176 / \mathrm{CER} / 13-2-04$

Publication date: April $30^{\text {th }} 2021$

\subsection{Introduction}

Artificial soil freezing is a special soil reinforcement technique that utilizes an artificial refrigeration circulating coolant (chilled brine or liquid nitrogen) to freeze pipes embedded in the ground, withdraw heat from the ground and turn natural soil into frozen soil, hereby enhancing the strength and stability of the ground. A continuous frozen wall around an underground project is formed as a supporting structure and watertight barrier so that the project can be constructed under the protection of the frozen wall. In recent years, with the construction of subway tunnels in many Chinese cities, the technique has been widely used in metro-running tunnel construction.

In many projects where it is desired to temporary stabilize and hydraulically seal soil and rock, chemical-or mineral-based grouting agents are used. Once the temporary construction has served its purpose, chemical-and mineral-based grouting substances are still remaining in the ground

When freezing, particularly fine-grained soil, a zone, referred to as the frozen fringe, and is formed between the frozen and the unfrozen soils where both unfrozen water and ice crystals exist in chaos. In the frozen fringe, a hydraulic pressure gradient arises, with pore water suction close to the frozen soil. The pore water suction forms a source to a pore-water flow against the frozen soil, where the water freezes and thus is able to form ice lenses. However, enriching of the soil water is a self-defeating process and together with the released part of the original pore water, a reasonable amount of settlement can be expected. When the frozen soil thaws, two opposite processes exist in the soil. There is consolidation, a reduction of porosity in connection with the pressure dispersion of the thawed water, and there is swelling of the clays. This condition is maintained at low pressures e.g. in soil near ground surface, and has the consequential effect that the soil void ratio increases. Thus, the effect is capable of resulting in a slight increase in the void ratio, particularly in soil close to the surface, and in a reduction in void ratio in the soil at deeper levels. If the soil after freezing and subsequent thawing has an increased void ratio, it means that the coefficient of consolidation of the thawed soil will be greater for the soil before freezing and vice versa (Tsytovich, 1975). One problem with the freezing of soil and rock is that fine-grained clayey types of soils have showed a tendency to under certain circumstances, during the thawing process, create a pore-water overpressure and to consolidate, despite a change in the external loading conditions. In certain cases, this condition can be a desired effect as the soil mass after a freeze and thaw cycle acquires over consolidated properties. During the freezing, mineral particles and water are restructured, and in some cases, segregated ice with ice lenses is created. Fractures in the frozen soil can also arise at the frost front during the freezing process and these phenomena can lead to the thawing deformations.

Nevertheless, these side effects can create problems in urban areas with interruptions in the surroundings and undesired costs if, for example, a slide takes place in a slope or if the ground area is subjected to significant continuous settlements. Such an example is the stabilization and the hydraulic sealing with retaining structure at the area of Tegelbacken during the building of the underground railway from Central station to Slussen station in the centre of Stockholm, 1952 (Berglund, Österberg, Schütz \& Heland, 1957). After the soil had thawed, large problems with consolidation settlements arose due to the freezing. 
During the freezing, mineral particles and water are restructured, and in some cases, segregated ice with ice lenses is created. Fractures in the frozen soil can also arise at the frost front during the freezing process. These phenomena can lead to the thawing deformations. A number of different equations describe the size of the thawing deformations. The equations, however, are in general based upon site-specific soil properties and are usually adapted to permafrozen soils.

\subsection{Motivation for the Study}

The main objectives of this article are to describe and review the knowledge and current state of practice of artificial soil freezing to increase the understanding about the study on mechanism of frost heaving and thawing in Construction of tunnel and to compare results from field test and Abacus simulation on the behavior of the mechanism during freezing process for a subway connection. Key simulation challenges of modeling soil freezing process in abacus simulator are noted next on the construction study concerns a twin tunnel at the Jiangyu Road Station subway in binjiang district, Hangzhou city, Zhejiang province in china. The model calibration and sample simulation results are presented next and we conclude this paper with a brief discussion on geomechanical monitoring and modeling

\subsection{Status Update}

In order to control the impact of frozen hole drilling, strata freezing and melting on tunnels and the ground, according to the latest research results and construction experience at home and abroad, the following technical points of frozen design are put forward:

(1) Drilling frozen holes in the tunnel, according to the structure of the contact channel using near-horizontal holes or beveled holes, each bore hole is set up hole pipe, and installed hole sealing device, in order to prevent a large amount of mud water from pouring out when drilling in. After each hole is completed, the square amount of the hole outflow is calculated in a timely manner, combined with the change of surface subsid on monitoring data, and the slurry is filled in time.

(2) The thickness and strength of the permafrost curtain should meet the requirements of the contact channel excavation, especially to ensure the horn port In particular, ensure the thickness of the frozen curtain at the horn port, while ensuring that the frozen curtain and tunnel tube pieces are fully glued. Do a good job of freezing and digging with the work, and according to the excavation after freezing curtain deformation situation timely adjustment excavation construction process.

(3) In order to reduce the effect of freezing expansion on the tunnel, a cold pipe and a heat insulation layer shall be laid on the side of the freezing station near the horn port. Reduce the distance between the frozen hole and the side tunnel tube, and adopt small opening distance, lower salt water temperature, large salt water flow and other measures to speed up the freezing speed, and in the appropriate parts of the pressure relief hole, in order to reduce the impact of soil permafrost on the tunnel.

(4) Monitor the formation process and formation of permafrost curtain through temperature measuring holes and pressure relief holes. Special monitoring of the collagen between the permafrost curtain and the opposite tunnel tube.

(5) Pre-buried slurry holes in the bottom plate, sides, top and bottom concrete of the contact channel, and drilling slurry holes in the tunnel pipes if necessary, in order to prevent ground subsid on caused by permafrost melting and the subsid on deformation of tunnels and contact channels. The monitoring of frozen formation temperature, the monitoring of formation subsid on deformation and the monitoring of tunnel deformation are carried out to guide the construction of the contact channel.

(6) In order to reduce the adverse effects of freezing and thawing, the uneven subsid on of the ground is controlled by using the natural thawing and thawing slurry scheme.

(7) Strengthen the frequency of surface subsid on monitoring, grasp the changes in surface subsid on in a timely manner, and then guide the construction.

(8) According to the actual conditions on the spot, the frozen engine room is intended to be placed in the tunnel or on the platform of the station, the temperature measurement system adopts the intelligent frozen temperature control system, and the temperature measurement data is collected and analyzed by the frozen monitoring cloud platform. Freezing station covers an area of about $150 \mathrm{~m}$ square, the station equipment mainly includes freezers, salt water tanks, salt water pumps and tank substations, water pumps and cooling towers. The installation of the equipment is carried out in accordance with the requirements of the equipment instruction manual. 


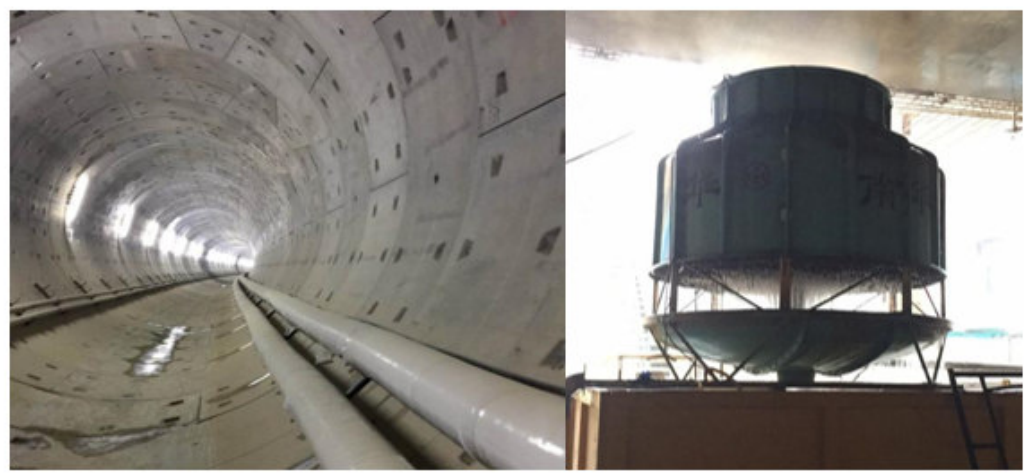

Figure 1: The freezer room is furnished

\subsection{Literature Review \\ 2.1 Ground Freezing}

The frost action and the phase change of water (from liquid to solid) in a soil body, due to freezing and thawing of soils, change the properties of the soil. It has been recognized that freeze-thaw cycling has a considerable impact on the structure and thus the geotechnical properties of soil. Most studies on the strength properties of thawing soils have been conducted under undrained conditions. Graham and $\mathrm{Au}(1985)$ have reported a significant loss in undrained shear strength soon after freeze-thaw cycles on clays. Studies on loose silt show the opposite behavior (Alkire \& Morrison, 1982) probably due to the compaction effects of the freeze-thaw cycles. Simonsen et al. (2002) have documented a significant reduction in the resilient modulus soon after freeze-thaw cycles.

During thawing, the soil may suffer from loss in strength, i.e., thaw weakening. The key factors influencing the loss in strength are the thaw rate, amount of frozen water in the voids and in segregated ice, the drainage ability of the soil, and the load the soil is carrying (Launonen \& Turunen, 1995; Doré, 2004; Shoop, Affleck, Haehnel, \& Janoo, 2008; among others). During thawing, the soil profile is partly frozen and the frozen part remains in layers. The frozen soil can be considered to be impervious due to the very low hydraulic conductivity in frozen soil (Watanabe \& Flury, 2008). Therefore, the released water from thawing is prohibited to drain downward due to the existing frozen soil and becomes trapped between the frozen zone and the surface

\subsection{Categories of Ground Freezing}

Large areas located in the northern hemisphere have naturally cold conditions; this concern especially sporadic-, seasonally- or permafrozen ground. During the previous centuries diverse activities like mining, oil exploitation has taken place in these areas. However, due to logistics, housing, construction etcetera, the frozen grounds as well as the thawing grounds have caused problems, among other things thaw settlement. To overcome these inconveniences, countries faced the problems started researching naturally frozen ground. For that reason, knowledge of naturally frozen ground is relatively well described. This section describes the essential differences and the main similarities between naturally frozen ground and artificially frozen ground. A brief description of the main characteristics in permafrost landscapes and its genesis are given. In fact, there are several similarities between naturally frozen and artificially frozen soil. Nevertheless, there are also many differences. By having knowledge of these differences, information from permafrost investigations and sciences can be used when designing artificially frozen constructions (Ladanyi \& Sayles, 1978; Freitag \& McFadden, 1997).

There are a lot of similarities between naturally frozen and artificially frozen soil, unfrozen water and ice lenses exist, for example, in both cases. Ice lenses are developed in the same way in both cases, i.e. parallel to the freeze front. The frequency and thickness of the ice lenses decrease with depth, i.e. a decrease because of increased stress. When naturally frozen and artificially frozen fine-grained soil thaws, thaw consolidation occurs (Ladanyi \& Sayles, 1978).

The artificially frozen construction in ground is created by installing freeze pipes (also called cooling-pipes) in the ground. To be able to freeze the ground to a certain temperature and so reach the desired strength and/or the desired waterproofing of the construction, one has to have knowledge of the material- and the geometric parameters so the time aspect and the necessary cooling effect can be judged. The agents of importance in regards to the freeze pipe design is (Jumikis, 1966; Shuster, 1980; Harris, 1995; Andersland \& Ladanyi, 2004; Johansson, 2005)

\subsection{History of Ground Freezing On Subway}

Artificial ground freezing (AGF) is a soil stabilization technique involving the removal of heat from the ground to freeze a soil's pore water. The concept of ground freezing was first introduced in France, and industrial applications date back to 1862 where it was used as a mine shaft construction method in South Wales (Schmidt 1895). The method was eventually patented by German mining engineer F.H. Poetsch in 1883 (sometimes termed 
Poetsch Process). The method involves a system of pipes consisting of an outer pipe and concentric inner feedpipes where a chilled coolant (calcium chloride brine, typically) is circulated. The coolant is pumped down the inner pipe and back up the outer pipe. It is then cooled again through a refrigeration process and returned through the pipe system. A further development on the AGF technique occurred in France in 1962, when liquid nitrogen (LN2) was pumped into the freeze pipes instead of chilled calcium chloride brine. This allows for much faster ground freezing if necessary. The liquid nitrogen runs through the freeze pipes and is allowed to evaporate into the atmosphere (Sanger and Sayles 1979). Currently, AGF has been applied to a wide variety of engineering projects where stability, groundwater conditions, and containment are an issue. Example situations include: vertical shaft construction for mining or tunneling, stabilization of non-engineered earth fills (large obstructions), sites that require horizontal access (e.g. a TBM canopy for cross passage construction), lateral and vertical contaminant containment, contaminant redirection, groundwater cutoff (can be tied into bedrock), and emergency support/stabilization using LN2 (Schmall and Braun 2006). During the process, heat is removed from the soil in a cylindrical pattern around freeze pipes. This produces columns of frozen soil. The columns continue to expand until they intersect. From here, the frozen mass will expand outwards creating a wall or solid ring of frozen soil (Sanger and Sayles 1979).

\subsection{Simulation Model for Soil Freezing}

The simulation of the soil freezing process was conducted with commercial simulator Abacus because of its modeling capability of water freezing and/or ice thawing processes. A general discussion on simulation models for ground freezing along with key modeling challenges has recently been provided in Co-simulations can be performed between Abacus Standard or Explicit and Abacus CFD. Abacus CFD is used for incompressible flows, or for low-speed air-flows to predict fluid behavior. Simulate in-compressible fluid dynamics, transient and steady state, fluid and solid heat transfer, natural convection and laminar and turbulent flows.

(1) Diminishing Porosity - As liquid water converts to solid ice; fluid porosity diminishes and numerical solutions to flow equations become more difficult and much slower. This situation was circumvented by a "rubbery fluid model" where a small amount of rock volume was repartitioned as a pseudo oleic component which does not change under freezing. The rubbery fluid component was assigned the same mass and thermal properties as that of the rock and a sufficiently high viscosity to minimize its mobility. To compensate for the effects of repartition, the initial void and fluid porosities, fluid saturation, and the end points of relative permeability curves were adjusted accordingly. This approach significantly improved simulation run performance.

(2) Freezing Point Depression (FPD) - The current Ice model in Abacus is based on pure water chemistry. FPD was effectively modeled by shifting the initial temperature of bulk volume upwards by the amount of freezing point depression at the water salinity in a prevailing water zone.

(3) Variation of Inter-Hole Distance - Conduction heat transfer is the dominant transport mechanism for formation of a freeze wall and as such, representation of freeze hole trajectories and thus honoring spacing between adjacent holes is crucial. This issue is discussed in some detail below when we describe the simulation model for the strata freezing and melting on tunnels.

\subsection{Description of the site Simulation Model}

Contact Channel and Pumping Station Engineering: Installation and commissioning completed on June 21, 2019 and power-on freeze, to July 31, 2019, has accumulated 41 days, the equipment is in good working order, water system and salt water system is working properly.

2. Contact Channel Project: Installation and commissioning completed on June 19, 2019 and power-on freeze, to July 31, 2019, has accumulated 43 days, the equipment is in good working order, the water system and salt water system is working properly

\subsection{Saltwater system}

(1) The Working Condition of the Freezer

The salt water cycle is all positive. Each frozen hole head to circuit temperature difference within $2{ }^{\circ} \mathrm{C}$, each freezer works normally.

(2) The working pressure and flow of the salt water pump

Salt water pump out-of-line pressure $0.40 \mathrm{MPa}$, circuit pressure $0.35 \mathrm{MPa}$, and go-loop pressure difference $0.05 \mathrm{MPa}$. The frozen holes are connected in series by 4 or 5 and divided into 10-12 groups, which are supplied by the distribution ring. The system selects a salt water pump with a power of $55 \mathrm{KW}$ and a flow rate of $400 \mathrm{~m} 3 / \mathrm{h}$. The average flow rate of a single hole can be as small as $8 \mathrm{~m} 3 / \mathrm{h}$, and the average flow rate of a single hole is $5 \mathrm{~m} 3 / \mathrm{h}$, which meets the design requirements.

(3) 1 Contact channel and pumping station project saline cooling situation

The salt water temperature is as follows, June 25 (the fourth day of power-on freezing), the salt water out-way temperature drops to $-18.0^{\circ} \mathrm{C}$, the circuit- $16.0^{\circ} \mathrm{C}$, July 5 (the 15 th day of power-on freeze), the salt water go-out 
temperature drops to $-28.0{ }^{\circ} \mathrm{C}$, the circuit $-26.5{ }^{\circ} \mathrm{C}$, as of July 31 has been maintained for 26 days below $-28{ }^{\circ} \mathrm{C}$, salt water out of the road temperature at $-28.8{ }^{\circ} \mathrm{C}$, circuit temperature $-27.2{ }^{\circ} \mathrm{C}$, according to the salt water go, circuit temperature, temperature difference, salt water cooling trend is normal.

(4) The cooling of salt water in the liaison channel project

The salt water temperature is as follows, June 21 (the third day of power-on freezing), the temperature of the salt water route drops to $-20.0{ }^{\circ} \mathrm{C}$, the circuit $-18.0^{\circ} \mathrm{C}$, June 29 (the 11 th day of the power-on freeze), the salt water out-way temperature drops to $-25.5^{\circ} \mathrm{C}$, the circuit- $24.0^{\circ} \mathrm{C}$, July 1 , salt The temperature of the water route dropped to $-28.0{ }^{\circ} \mathrm{C}$, the circuit $-26.5{ }^{\circ} \mathrm{C}$, as of July 31 has been maintained for 31 days below $-28{ }^{\circ} \mathrm{C}$, the salt water out route temperature is $-28.0^{\circ} \mathrm{C}$, the circuit temperature is $-26.7^{\circ} \mathrm{C}$, according to the salt water go, circuit temperature, temperature difference, the trend of salt water cooling is normal.

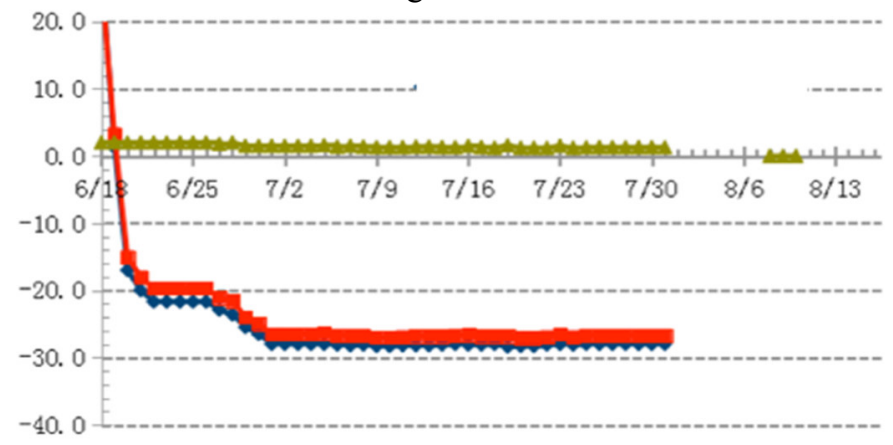

Figure 2: Salt Water Go, Circuit Temperature - Time Change Curve

Where the blue color is the way to salt water, red color is brine circuit, green color is temperature.

From the salt water go, circuit temperature, the saline cooling range is relatively normal

\subsection{Pressure Relief Hole}

According to the actual situation, 2 pressure relief holes were set up in the left and right line excavation section 6 . From 4 July, the pressure of the relief hole is monitored, and the pressure change curve is shown in Figure 3.

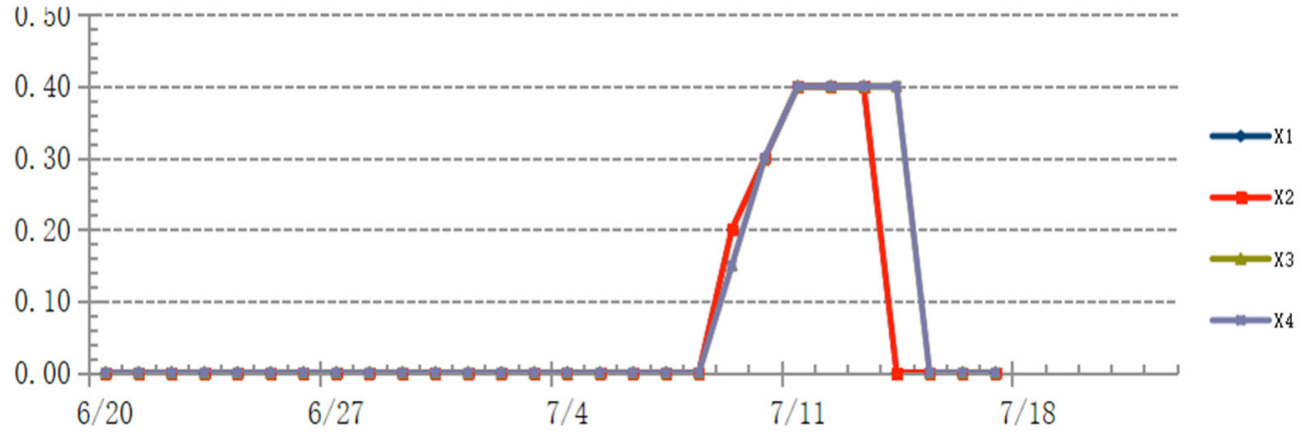

Figure 3: Pressure Relief Hole Pressure - Time Change Curve

Left and right line pressure relief hole from around July 9 began to continue to grow, July 11 pressure increased to about $0.40 \mathrm{MPa}$; From the pressure data change analysis of the pressure relief hole, the curtain is frozen before July 9 begins to form a closed body. Frozen curtain has formed self-reliance, able to resist soil and water pressure, pressure relief holes without the phenomenon of mud drip.

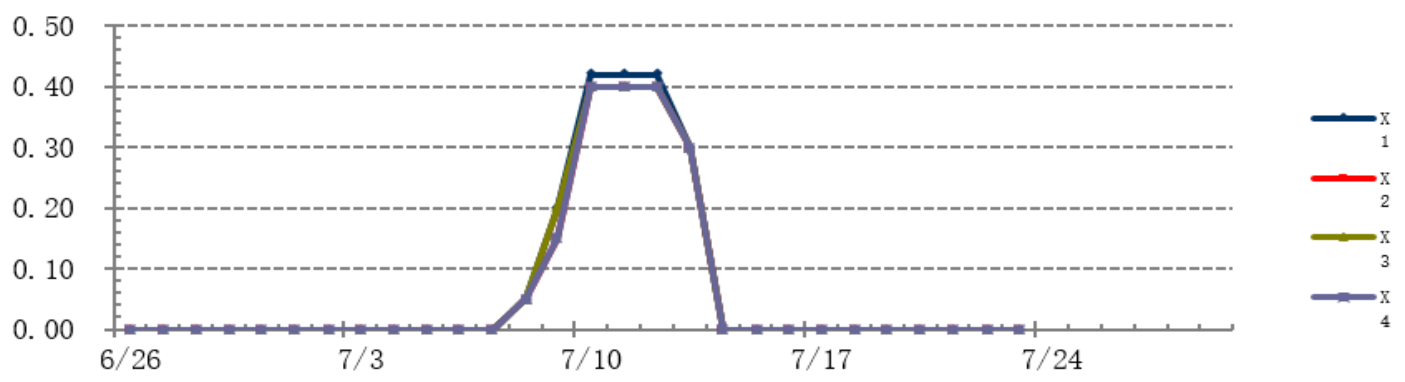

Figure 4: Pressure Relief Whole Pressure - Time Change Curve

Left and right line pressure relief hole from around July 8 began to continue to grow, July 10 pressure increased to about $0.42 \mathrm{MPa}$; From the pressure data change analysis of the pressure relief hole, the frozen curtain began to form a closed body before July 8 . Frozen curtain has formed self-reliance, able to resist soil and water 
pressure, pressure relief holes without the phenomenon of mud drip. Through the above freeze effect analysis and on-site actual excavation preparations, has now met the excavation conditions, the ministry applied for excavation on August 5, 2019.

Contact Channel and Pumping Station Engineering Temperature Hole Drop Graph (C1-C9)
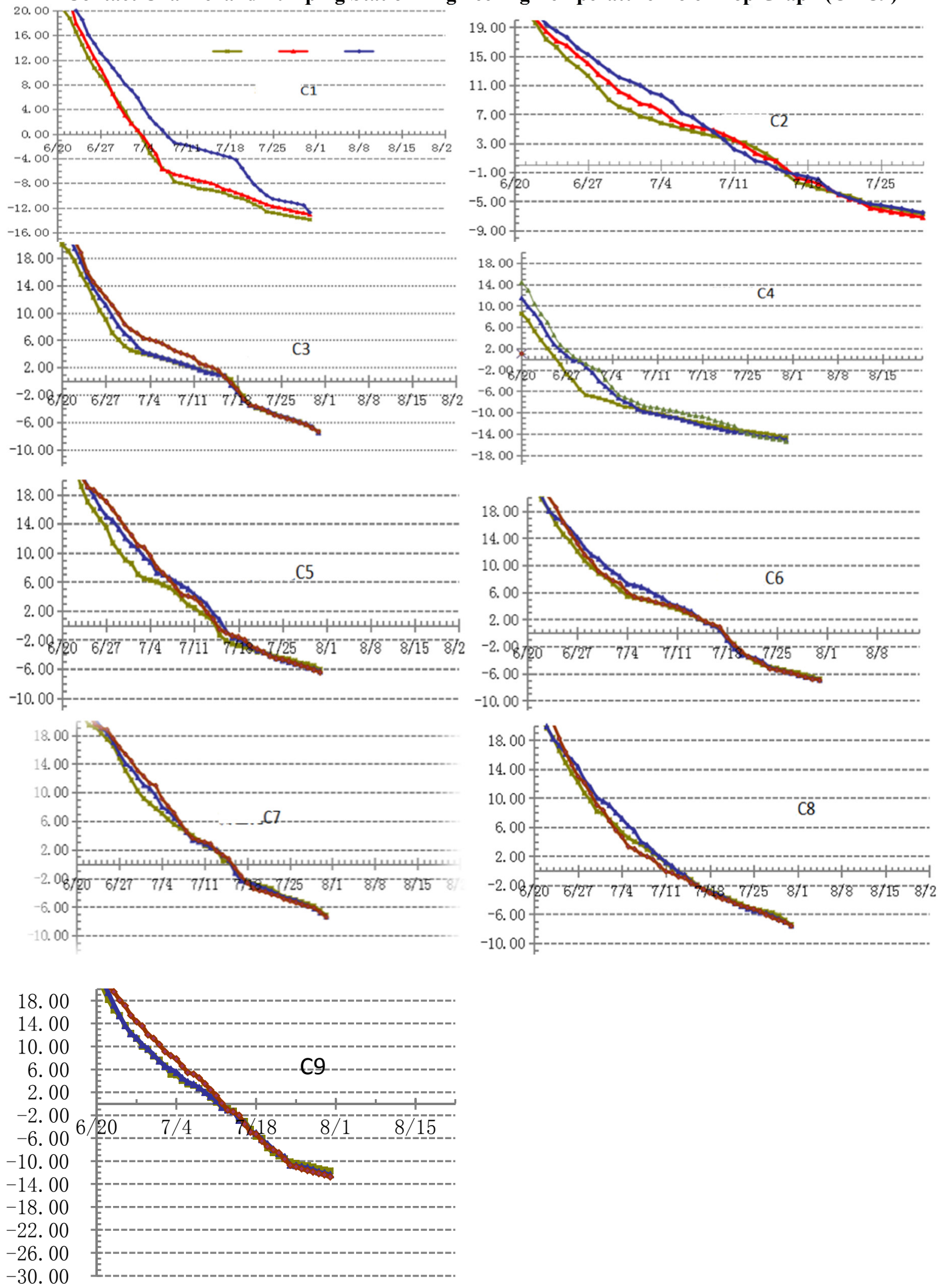

Figure 5: Dropping Temperature Hole 


\subsection{Computational Modeling}

The validated computation model for soil freezing is applied to the simulation of Artificial soil freezing for the temporally soil support during tunneling. To obtain frozen soil with high bearing capacity and impermeability, freeze pipes with a fixed temperature of $-35^{\circ} \mathrm{C}$ and a diameter of $0.2 \mathrm{~m}$ are installed horizontally in a soil layer initially at an in-situ ground temperature of $13.45^{\circ} \mathrm{C}$, which rests on a rigid impervious base (depth: $10 \mathrm{~m}$, width: $38 \mathrm{~m}$ ). The inner surfaces, where the freeze pipes are located, remain immobile and undrained A three -dimensional soil freezing simulation is conducted in order to investigate the development of the freezing process under a tunnel construction from strain/stress, temperature and void ratio mechanism

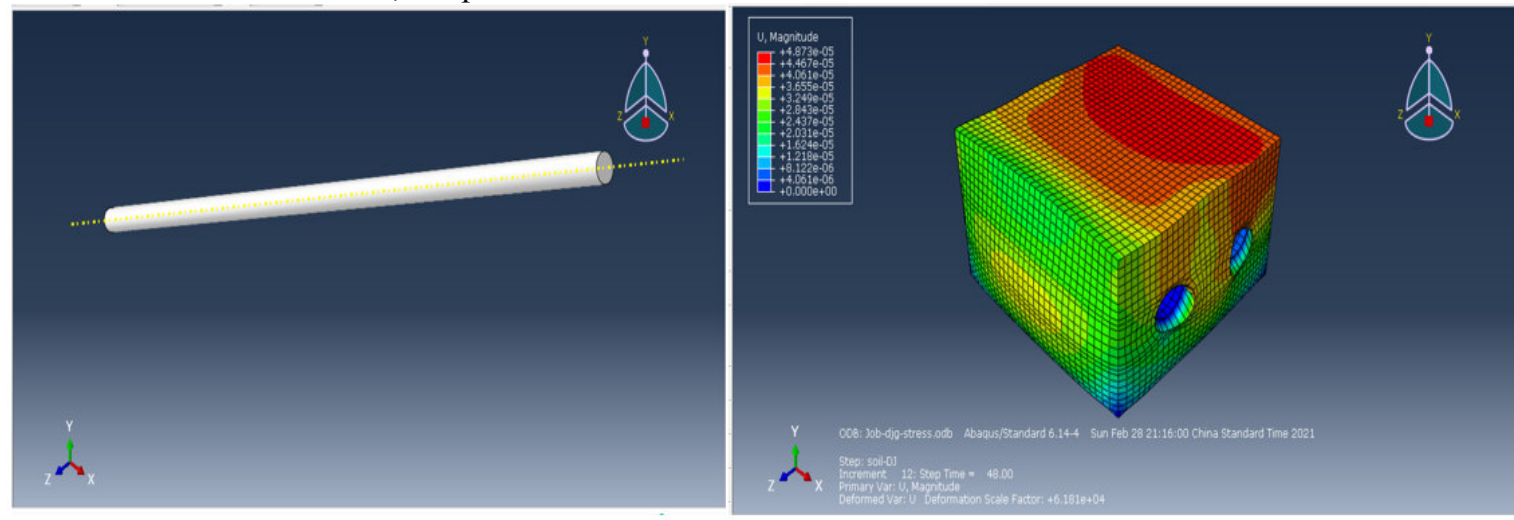

Figure 6: Pipe Of the Soil Freezing and 3 Dimensions Deformed Soil Sample with Ice Saturation Profiles
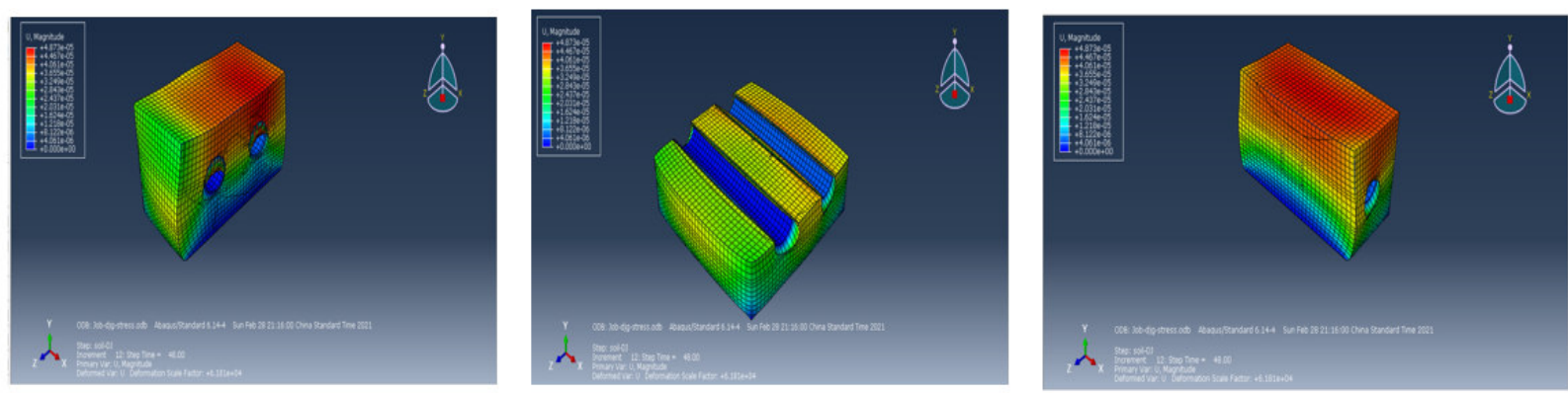

Figure 7: x, y, z Directions of the Deformed Soil Samples with Ice Saturation Profiles (Deformation)

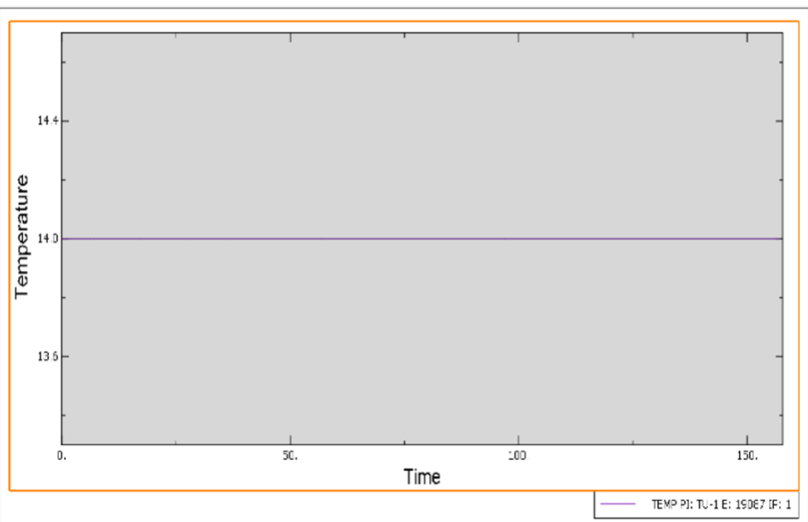

Figure 8: temperature at a horizontal point

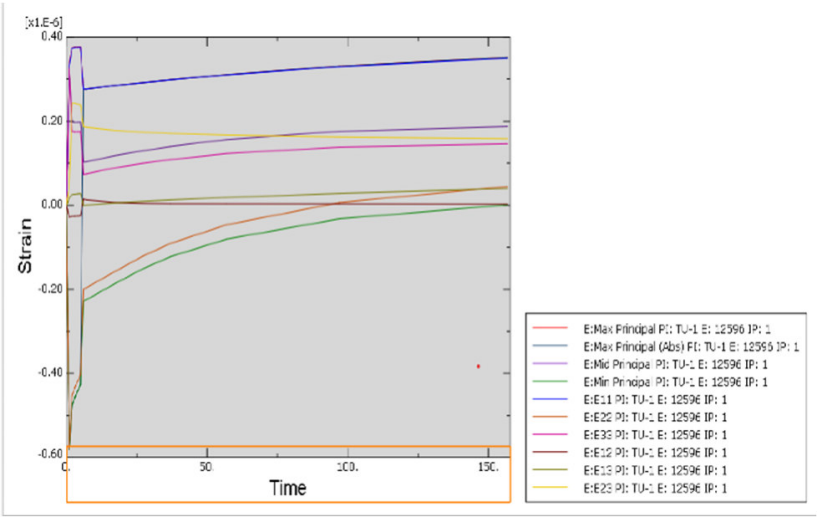

Figure 9: strain at a horizontal point 


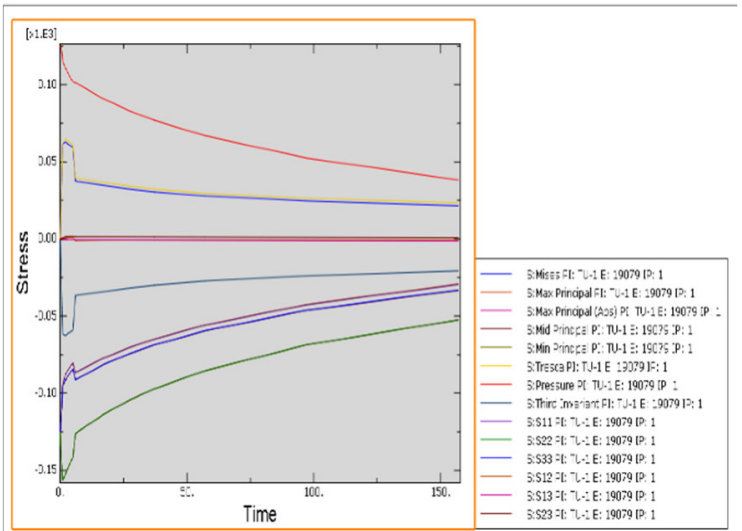

Figure 10: Stress At a Horizontal Point

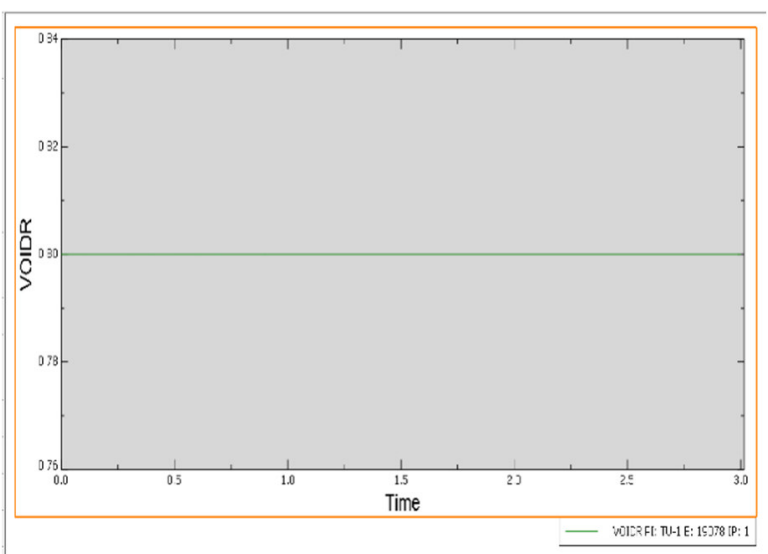

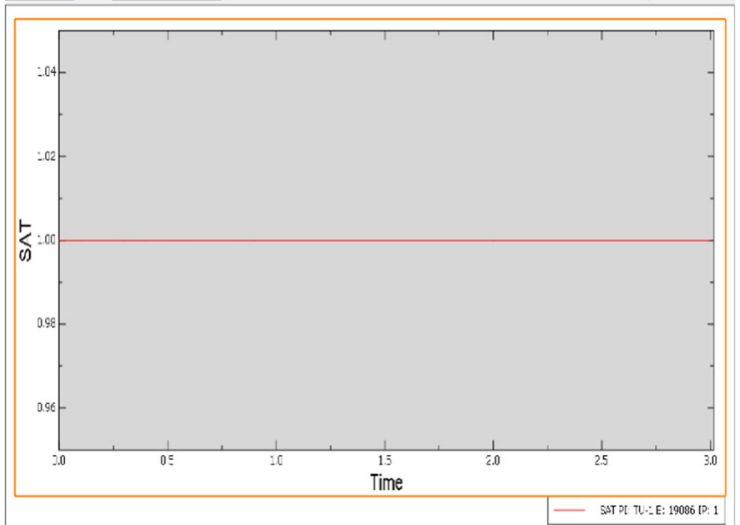

Figure 11: Saturation at a Horizontal Point

Figure 12: Void Ratio at a Horizontal Point

The Hangzhou metro(tunnel) construction study is a good example of the application of both brine and liquid nitrogen methods of Artificial soil freezing, and provides a comparison of timescale for each method as implemented in field conditions.

\subsection{Final Remarks}

It is well known that, when dealing with soil improvement techniques, soil freezing represents a rather unique solution for difficult soil and ambient conditions. At the same time, this technique cannot be considered as a routine technique, because it requires expertise, both in the design and the mechanics, acquired with quite a large variety of projects in order to judge its capability and application for the use on a given project.

Artificial soil freezing is implemented in the field using a mobile refrigeration plant, which circulates chilled calcium chloride brine through freeze pipes, removing heat from the soil and freezing the soil's pore water. Also, liquid nitrogen may also be used, however it is allowed to evaporate into the atmosphere rather than being recirculated. A number of design considerations must be taken into account such as freezing time, freeze pipe spacing, groundwater velocity, saturation, pore water salinity, estimated soil heave, and costs. Temperature of the soil and coolant, as well as soil heave, settlement, and pressures on existing structures as well as the freeze pipes are important to monitor while implementing an artificial ground freezing program. Overall, artificial ground freezing has a wide variety of applications, and a history of successful application in the field. It has become economically competitive with traditional ground stabilization methods and has the ability to be applied to a wide variety of projects. Analysis of the test data revealed that the two main components of a frozen soil influence the strength parameter of the compound material differently. The ice influences the cohesive part, whereas the density of the solid particles controls the friction mobilized. Therefore, strain rates or temperatures only affect the cohesion. This also implies that the minimum strength of a frozen granular soil is equal to the critical state strength of the unfrozen granular soil. Comparisons between field tests and computation simulation showed a close connection in terms of the results obtained. Each test is a special form of the other, and therefore similar responses have to be expected. Hence, a fast field test is equivalent to simulation with constantly changing loads that only allows primary creep deformations to develop. However, the relationships presented are only a first approach toward modelling real soil behavior. It is important in engineering practice to have a collection of well documented case study. This paper is aimed to contribute in this respect, by showing the test field and computation simulation to solve a difficult condition during the study on mechanism of frost heaving and thawing in construction of tunnel- 
channel freezing method.

\section{Acknowledgements}

The authors would like to thank Doctor Luo ZhanYou for discussions and his helpful comments on an earlier version of this paper.

\section{REFERENCES}

Tsytovich, N. (1975). The Mechanics of frozen ground. Washington, DC: Scripta book co.

The stabilization and the hydraulic sealing with retaining structure at the area of Tegelbacken during the Building of the underground railway from Central station to Slussen station in the centre of Stockholm, 1952

Berglund, H., Österberg, S., Schütz, F. \& Heland, H. von (1957). Teknisk beskrivning av Stockholms tunnelbana (Tech rep). Stockholm: Norstedt \& Söner.

Graham, J. \& Au, V.C.S. (1985). Effects of freeze-thaw and softening on natural clay at low stresses. Can Geot J, vol (22). Pp 69-78.

Alkire, B. and Morrison, J., 1982. Change in soil structure due to freeze-thaw and repeated loading. Transportation Research Record 918: 15-22.

Simonsen et al. (2002) suggested that after a completed freeze- thaw, the soil displays a decrease of Approximately $20-60 \%$ in resilient modulus depending on the soil type.

Launonen, P., \& Turunen, P. (1995). Sään ja hydrologisten tekijöiden vaikutus kevätkelirikkoon. (Finnish) Roadex I Project 19988-2001. Northern Priphery. CD- ROM.

Doré, G. (2004). Development and validation of the thaw-weakening index. International Journal of Pavement Engineering, 5(4), 185-192

Shoop, S., Affleck, R., Haehnel, R., \& Janoo, V. (2008). Mechanical behavior modeling of thaw-weakened soil. Cold Regions Science and Technology, 52, 191-206

Watanabe, K., \& Flury, M. (2008). Capillary bundle model of hydraulic conductivity for frozen soil. Water Resources Research, 44(12).

Ladanyi .B. And Sayles, F.H. 1978. General Report Session II: Mechanical Properties. Proceedings of The Fist International Symposium on Ground Freezing. Bochurn. pp. 7-18.

Freitag, D. R., \& McFadden, T. T. (1997). Introduction to Cold Regions Engineering (p. 738). American Society of Civil Engineers.

Jumikis, A.R. (1966) Thermal soil mechanics. Rutgers University Press, New Jersey.

Huster, J. (1980). Engineering quality assurance for construction ground freezing. $2^{\text {nd }}$ Int symp on ground Freezing, Norway, Trondheim. Pp 863-879.

Harris J.S., Ground Freezing in Practice, London, 1995.

Johansson, T. (2005). Frysning av jord och berg vid tunnelbyggande. Studier av deformationer och spänningar, Tapp 1. Licentiate thesis (in Swedish), KTH, Div of Soil and Rock Mech.

Andersland, O. B., \& Ladanyi, B. (2004). Frozen ground engineering (2nd ed.). Hoboken: Wiley

Wales Schmidt, M.F. (1895). "L'emploi de la congelation pour l'execution de travaux dans les terrains aquiferes (Use of freezing for work in water bearing ground)." Bull. Soe.

F.H. Poetsch in 1883. First developed the artificial ground freezing (AGF) method.

Sanger, F.J. and Sayles, F.H. (1979). "Thermal and theological computations for artificially frozen ground Construction." Eng. Geol., 13, 311-337

Schmall, P. and Braun, B. (2006). "Ground Freezing — A Viable and Versatile Construction Technique." Cold Regions Engineering 2006, 1-11. 